\title{
SIMULATION OF HELICAL GEAR FORMING OF AZ31 MAGNESIUM MATERIAL
}

\author{
Önder Ayer ${ }^{1}$ \\ 1 Trakya University, Department of Mechanical Engineering, Edirne, Turkey, e-mail: onderayer@trakya.edu.tr
}

Received: 2017.03.15

Accepted: 2017.05.05

Published: 2017.06.01

\begin{abstract}
The simulation of helical gear forming is investigated in this study. AZ31 type magnesium material was selected for workpiece material because of its high specific strength. The finite element method was used to simulate the closed die upsetting method for magnesium material of helical gear upsetting. Three dimensional finite element analyses were carried out to obtain the forming load, effective stress, effective strain and temperature change with DEFORM-3D software.
\end{abstract}

Keywords: AZ31, Gear forming, Helical gears, FEM, DEFORM-3D.

\section{INTRODUCTION}

It is well known that gears were used for irrigation systems in Mesopotamia. Romans used cast bronze or iron gears for longer service life in ancient times. Nowadays, gears are used in several areas such as transmissions, complex machines and so many different industrial applications. Gears are generally manufactured by machining or by a combination of conventional hot forging with machining requiring a lot of manufacturing time, which means more expensive manufacturing. Instead of conventional machining, plastic deformation processes can be used for the manufacturing of gear forms because of their advantages. Injection upsetting is a plastic deformation process in which a block/billet is reduced in cross-section by forcing it through the closed die with the desired shape of a final product.

Gear manufacturing is generally carried out with conventional methods such as form milling and broaching. In form milling, the tool called a form cutter travels axially along the length of the gear tooth at the appropriate depth to produce the gear tooth. After each tooth is cut, the tool is withdrawn, the gear blank is rotated, and the cutter proceeds to cut another tooth. The process continues until all teeth are cut. Broaching can also be used to manufacture gear teeth and is particularly applicable to internal teeth. The process is rapid and produces a fine surface finish with high dimensional accuracy. However, because broaches are expensive and a separate broach is required for each size of gear, this method is suitable mainly for high-quantity production. These aforementioned conventional manufacturing processes mainly cause the high amount of material loss for mass production. Conversely, the bulk forming processes like forging are generally preferred for material savings and much more important than this; the bulk forming processes improves the mechanical strength of the workpiece due to grain refinement and unbroken grain flow $[5,10,13$, $14,18]$. In addition to this, the forged parts are almost without holes and pores $[4,11]$. The injection upsetting method was one of the bulk forming methods and is specialized to form intricate shapes. And, for metal forming operations forming load is the most important parameter and so, it is important to estimate the forming load for the metal forming processes for optimal die design and selecting press capacity $[3,7,9,14]$. Mathematical methods are getting used more commonly in recent years to simulate the forming load and other process parameters which affect the quality of the product and it is possible to obtain optimum die design. The Finite Element Method is useful for the accurate prediction of forming 
loads, strains and stresses for forming gear like elements such as spur gear.

DEFORM-3D software is one of the powerful FEM based commercial pieces of software, which is specialized for metal forming operations like extrusion, forging and so on. The software is effective at saving costs and delays of trial-error approach in industrial forming operations [6]. There are several researchers studied on the FEM method to simulate the gear forming [1]. Chen et al. [10] used DEFORM-3D software to examine the separate influences of process parameters on the plastic deformation behavior of an aluminum billet extrusion. Behrens [4] investigated closeddie cold sizing process of a straight-toothed planetary gear in terms of the occurring elastic die deflection. Chitkara and Bhutta [11] investigated the upsetting of spur gear forms both experimentally and mathematically. Xu et. al. [21] analyzed the deformation characteristics and revealed the mechanisms of spinning defects and the influences of process parameters. Pérez et. al. [15] investigated the isothermal forging of two different gears from material which was deformed initially by Equal Channel Angular Pressing (ECAP). Pepelnjak et. al. studied the simulation of the warm forging of magnesium alloy in digital environment. [20] Paltasingh et. al. studied the experimental and dynamic simulation study of lateral extrusion of spur gears with involute tooth profile in terms of load requirement, die filling and material flow. Effective stress and strain, die filling, flow patterns and prediction of extrusion loads were examined with three dimensional finite element software and a series of experiments has been carried out [16]. Xu et. al. investigated a multi-pass stagger spinning process of internally toothed gear from plate blank through FEM simulation and experiments [21]. Pater established a FEM model with DEFORM 3D software for the rolling of gear and conducted experiments which demonstrate the effectiveness of the proposed method for forming spur gears $[17,18]$.

Helical gears are basically very similar to spur gears. Helical gears work more smoothly and quietly compared to spur gears. Spur gears make a characteristic whine at high speed and for this reason spur gears are used in low-speed applications. Conversely, helical gears are used in high-speed applications, large power transmission, or where noise abatement is important. The lower speed value for pitch line velocity is $25 \mathrm{~m} / \mathrm{s}$.
Selecting work piece material is the starting point to obtain the optimum production method and achieve better physical and mechanical properties for the product. Also there is more to it than that, such as saving weight is generally a main objective to select the workpiece material for the last decade. Magnesium offers so many advantages with having higher specific strength and lower density comparing to other engineering materials such as steel and aluminum. The most relevant alloys for the production of magnesium forgings are AZ80, ZK30, ZK60 and WE alloys. AZ alloys show a good combination of strength and ductility as well as a good corrosion resistance as high purity alloys [5]. In this study, FEM based software DEFORM was used to simulate the forging of helical gear of AZ31 material for $623 \mathrm{~K}$.

\section{MATERIALS AND METHODS}

In the presented study, helical gear form is one of the most used gear types for higher speed and higher torque applications. The helical gear has 24 teeth where module value is selected as 1.23. Pitch diameter and root diameters for gear were selected as $\varnothing 32 \mathrm{~mm}$. and $\varnothing 27.20 \mathrm{~mm}$ respectively. The helix angle of helical gear is $8^{\circ}$ and pressure angle was selected as $20^{\circ}$ for the study. Injection upsetting process was used to form AZ31 Magnesium material. The workpiece material diameter is $\varnothing 30 \mathrm{~mm}$. and its height is defined as $50 \mathrm{~mm}$. for the CAD model.

The workpiece material is selected as AZ31 type Magnesium. The AZ31 magnesium finds applications in areas for different purposes, especially in the automotive industry due to its high specific strength. AZ31 can be super-formed at elevated temperatures [8], hence, the process temperature was simulated at $623 \mathrm{~K}$ which is the suitable forming temperature for AZ31 magnesium material.[20][14]

The deformation characteristics of magnesium material are improved with the relaxation of additional prismatic and pyramidal gliding planes. These gliding planes severely increase the formability above $500 \mathrm{~K}$. The die materials were selected from the DEFORM-3D material library. The die material was selected as H13 for all die components. The selected product profile is complex and so mesh distribution is homogenized for work-pieces. Mesh density was determined for work-piece material at 300.000 elements. Higher mesh density gives more accurate FEM results. 


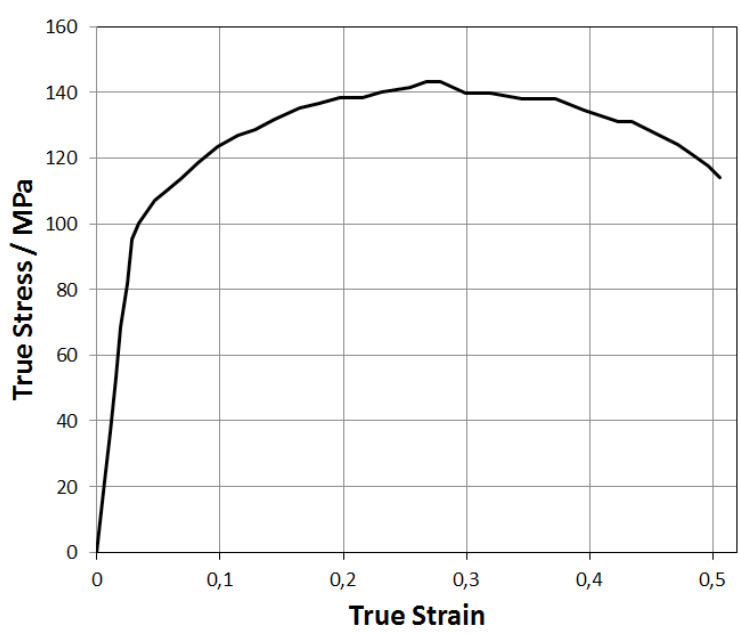

Fig. 1. True Stress-Strain curve of AZ31 for $623 \mathrm{~K}$

The global remeshing was chosen and the type of interference depth was selected as relative. A direct iteration method was selected for initial estimations and the Newton-Raphson method was used to obtain a rapid final convergence for the rest of the calculations. The friction factor $(\mathrm{m})$ for all contact surfaces was selected as 0.4 .

The flow stress equation was calculated from the tensile tests for $623 \mathrm{~K}$ temperatures is given as:

$$
\sigma=111 \varepsilon^{0.189} \mathrm{MPa}
$$

The CAD model was given in Figure 2.

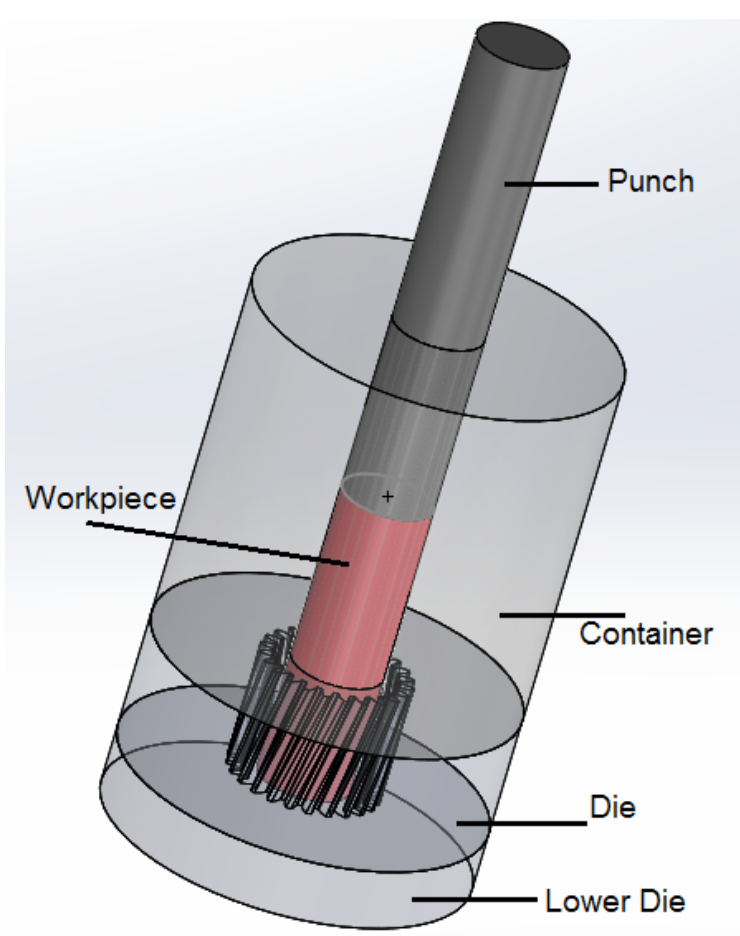

Fig. 2. CAD model of die setup

\section{RESULTS AND DISCUSSIONS}

The FEM model was built in DEFORM 3D software. The load-displacement diagram with FEM model is given in Fig. 3. The displacement value was calculated for workpiece to fulfill the die cavity as $18 \mathrm{~mm}$. The diagram can be divided into two different stages. At the first stage, the material is compressed and upsetting takes place at the same time until the end of the contact of the material with the die wall. At the second stage, extrusion process occurs and material flows laterally with the movement of the punch and it continues until the filling of the die cavity. The die filling ratio is one of the main parameters for the injection upsetting process. The die filling ratio is calculated from the simulation results as $99.2 \%$ for the proposed FEM model. In a similar study, Wang et. al. [19] observed an underfilling problem in their study. It can be seen that maximum forming load is achieved at $25 \mathrm{~mm}$. punch displacement and obtained as $77 \mathrm{kN}$.

Fig. 4 and fig. 5. illustrates that load versus stroke with effective stress diagram. The effective stress gives a perspective to press capacity, die design and suitable material flow of workpiece hence effective stress values were obtained from FEM study. In Fig.4. effective stress diagram is given for different punch displacement. The stress value starts with $110 \mathrm{MPa}$ and reaches to $150 \mathrm{MPa}$ maximum at the end of the process. The maximum stress is seen at the tip of the teeth on the die cavity surfaces as expected. The maximum effective stress value is observed as $150 \mathrm{MPa}$. The die cavity consists of so much shear stress which causes material flow inside. The detailed view can be seen in Figure 5 for effective stress of $25 \mathrm{~mm}$. punch displacement.

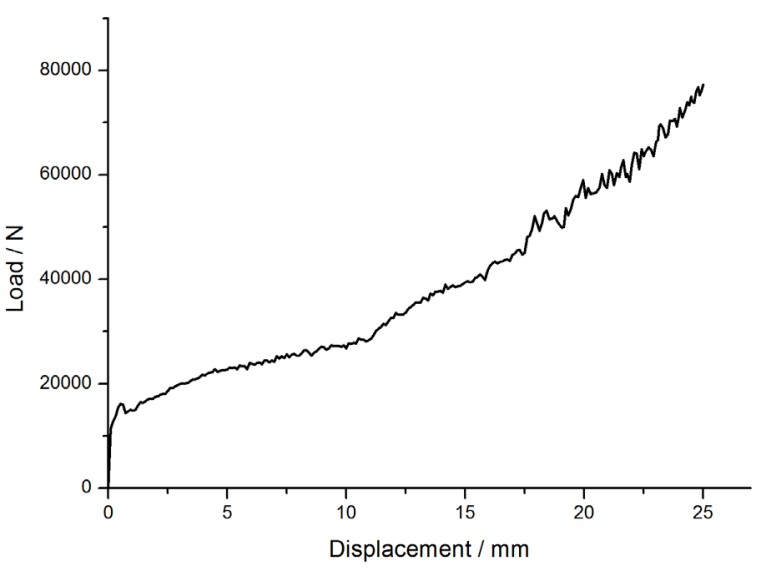

Fig. 3. Load-Displacement diagram with FEM model 


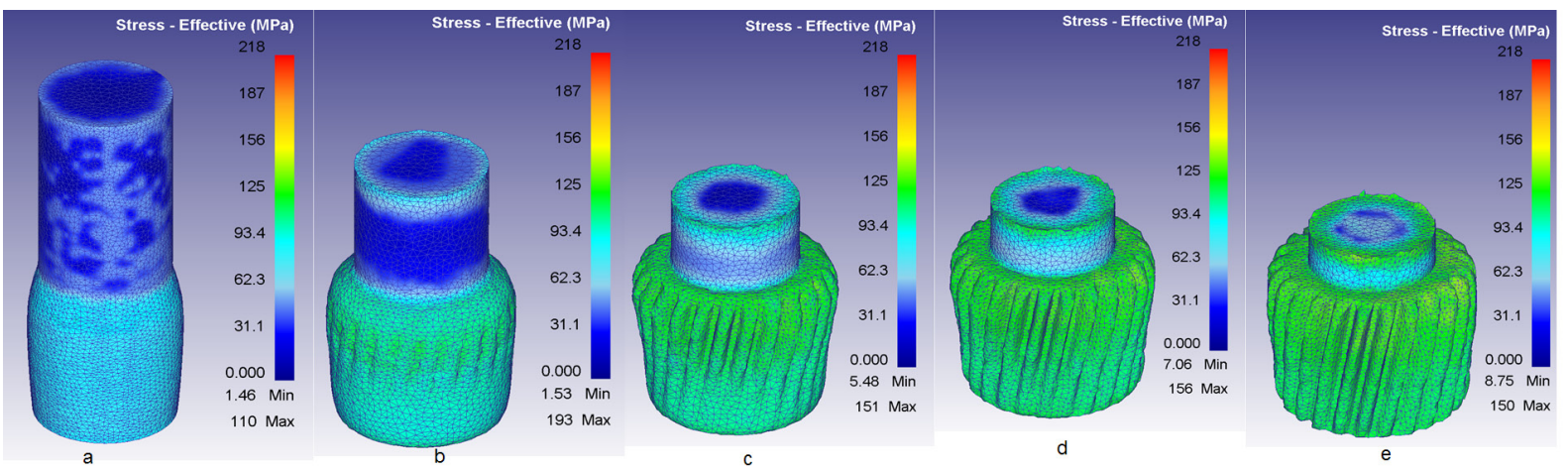

Fig. 4. Effective Stress diagram for different stroke values a-) $5 \mathrm{~mm}$, b-) $15 \mathrm{~mm}$, c-) $20 \mathrm{~mm}$, d-) $23 \mathrm{~mm}$, e-) $25 \mathrm{~mm}$

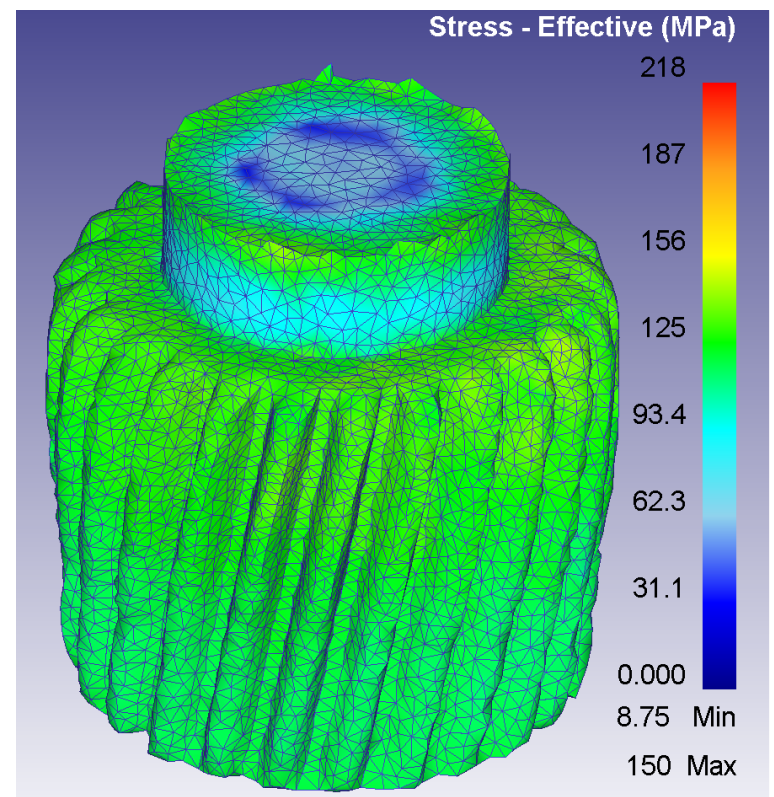

Fig. 5. Effective Stress diagram for $25 \mathrm{~mm}$ punch displacement

Effective strain distribution is seen in Fig. 6. for the maximum material flow point at $25 \mathrm{~mm}$. punch displacement. It is observed that the peak value for effective strain reaches $4.86 \mathrm{~mm} / \mathrm{mm}$. The maximum value is observed at corner of the die teeth. When the workpiece passes into the deformation region from the shaft to the die cavity, the material flow is not homogenous. The generated velocity field leads to unbalanced strain distribution and underfilling defects for the final product. Hence, it is very important to estimate the strain value for the designating the die.

The temperature change is given in Fig. 7. Initial workpiece, die and punch temperatures are defined as $350{ }^{\circ} \mathrm{C}$. The temperature change obtained from the FEM study which can be seen from Fig.7. is about $40^{\circ} \mathrm{C}$. This change is the result of inner deformation of the workpiece during forming. The temperature increases with the increase of material flow and the increase of strain

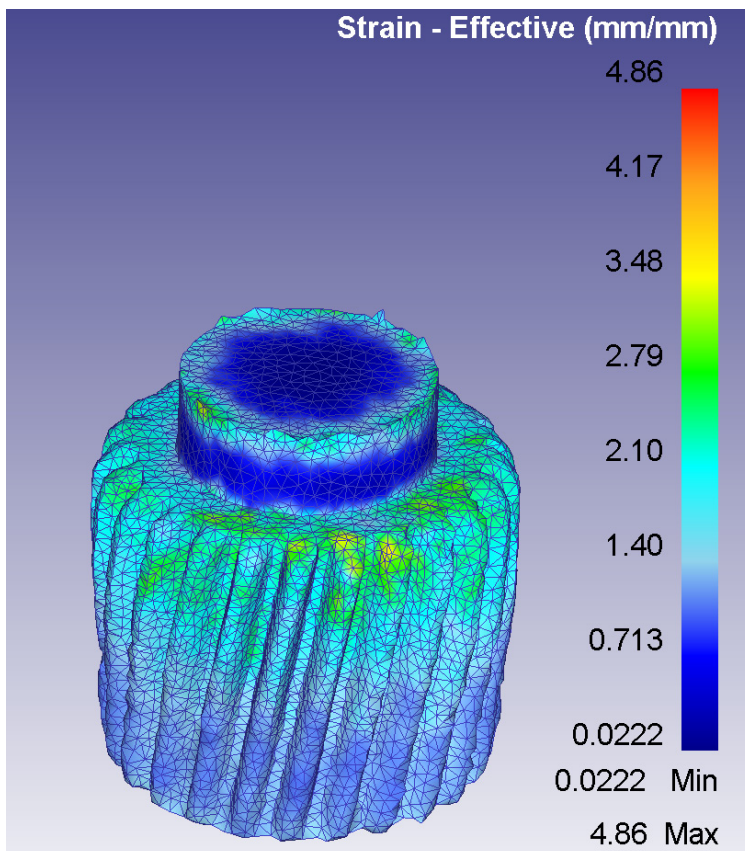

Fig. 6. Effective Strain diagram for $25 \mathrm{~mm}$ punch displacement

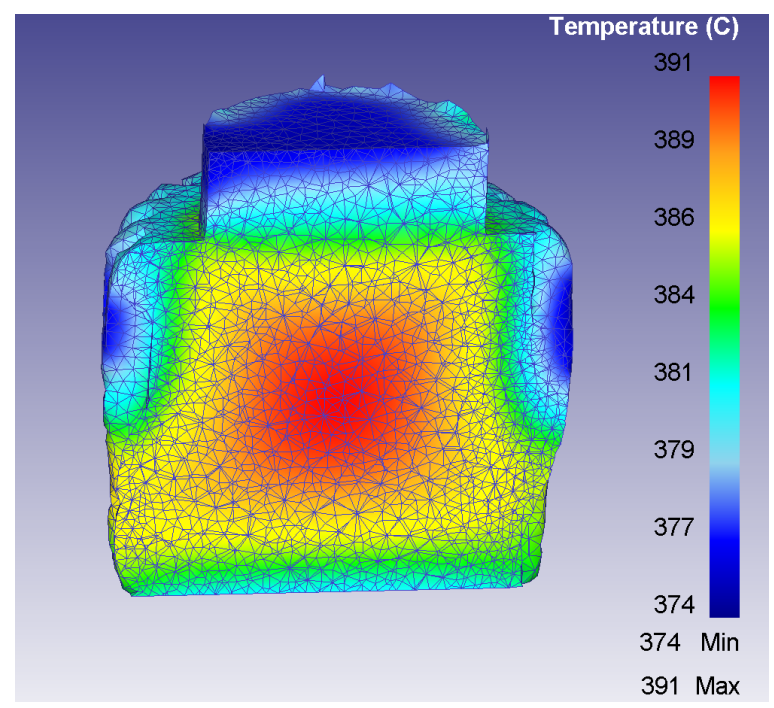

Fig. 7. Temperature distribution for $25 \mathrm{~mm}$. punch displacement 
caused by inner velocity discontinuities. In the shaft, the least change occurs because there is not a considerable amount of forced material flow.

\section{CONCLUSIONS}

Finite Element Method was used to simulate the gear forming with AZ 31B magnesium material. FEM based software named DEFORM 3D was selected for the FEM study. Based on the obtained results the following conclusions were derived:

- It is seen from the Load-Displacement diagram that load increases while material is filling the gear form.

- Effective stress distribution is homogeneous through the die cavity and maximum stress value is observed on the gear form region of die cavity.

- The strain distribution is not homogenous for helical gear form because of forced material flow and the process parameters such as punch velocity and die design should be reconsidered to prevent underfilling.

- The FEM study gives foresight into important process parameters like forming load, material flow and temperature distribution for an optimum die design and preventing defects for helical gear upsetting.

\section{REFERENCES}

1. T. Altinbalik, O. Ayer, Effect of die inlet geometry on extrusion of clover sections through curved dies: Upper bound analysis and experimental verification, Trans. Nonferrous Met. Soc. China (English Ed. 23 (2013) 1098-1107.

2. T. Altinbalik, Ö. Ayer, A theoretical and experimental study for the load optimization of gear-like profiles by using forward and lateral extrusion, Trans. Can. Soc. Mech. Eng. 39 (2015) 53-69.

3. T. Altinbalik, Y. Can, An experimental study of lateral extrusion of splines, Mater. Des. 27 (2006) 727-734.

4. B.-A. Behrens, E. Doege, Cold Sizing of Cold- and Hot-Formed Gears, CIRP Ann. - Manuf. Technol. 53 (2004) 239-242.

5. B.A. Behrens, I. Pfeiffer, J. Knigge, Forging technology for magnesium alloys, in: Adv. Wrought Magnes. Alloy. Fundam. Process. Prop. Appl., 2012: pp. 376-389.

6. S. Bingol, The Decreasing of the Extrusion Time with Varying Ram Speed, Mater. Manuf. Process. 30 (2015) 1185-1189.
7. S. Bingöl, Ö. Ayer, T. Altinbalik, Extrusion load prediction of gear-like profile for different die geometries using ANN and FEM with experimental verification, Int. J. Adv. Manuf. Technol. 76 (2014) 983-992.

8. S. Bingöl, W. Misiolek, Prediction of the true stress of ZE20 magnesium alloy at different temperatures and strain rates, Stroj. Vestnik/Journal Mech. Eng. 61 (2015) 610-617.

9. J. Cai, T.A. Dean, Z.M. Hu, Alternative die designs in net-shape forging of gears, J. Mater. Process. Technol. 150 (2004) 48-55.

10. D.C. Chen, S.K. Syu, C.H. Wu, S.K. Lin, Investigation into cold extrusion of aluminum billets using three-dimensional finite element method, J. Mater. Process. Technol. 192-193 (2007) 188-193.

11. N.R. Chitkara, M.A. Bhutta, Near-net shape forging of spur gear forms: An analysis and some experiments, Int. J. Mech. Sci. 38 (1996) 891-916.

12. J.C. Choi, Y. Choi, A study on the forging of external spur gears: upper-bound analyses and experiments, Int. J. Mach. Tools Manuf. 38 (1998) 1193-1208.

13. E. Doege, R. Bohnsack, Closed die technologies for hot forging, J. Mater. Process. Technol. 98 (2000) 165-170.

14. W. Guo, Q. Wang, B. Ye, H. Zhou, Microstructure and mechanical properties of AZ31 magnesium alloy processed by cyclic closed-die forging, J. Alloys Compd. 558 (2013) 164-171.

15. C.J. Luis Pérez, D. Salcedo Pérez, I. Puertas Arbizu, Design and mechanical property analysis of ultrafine grained gears from AA5083 previously processed by equal channel angular pressing and isothermal forging, Mater. Des. 63 (2014) 126-135.

16. U.C. Paltasingh, S.K. Sahoo, P.R. Das, K.C. Nayak, S. Potnuru, Lateral extrusion of spur gears with involute profile: Finite element analysis and experimental investigation, 3 (2013) 20-30.

17. Z. Pater, A FEM Analysis of Cross-Wedge Rolling of Toothed Shafts, 15 (2011) 50-58.

18. Z. Pater, A. Gontarz, A. Tofil, Analysis of the crosswedge rolling process of toothed shafts made from 2618 aluminium alloy, J. Shanghai Jiaotong Univ. 16 (2011) 162-166.

19. W. Wang, J. Zhao, R. Zhai, A forming technology of spur gear by warm extrusion and the defects control, J. Manuf. Process. 21 (2016) 30-38.

20. R. Werkhoven, D. Kobold, K. Kuzman, D.D. Centre, Analyses of Warm Magnesium Forging in Digital Environment, 35 (2015) 13-24.

21. W. Xu, X. Zhao, D. Shan, J. Li, Q. Deng, X. Cui, et al., Numerical simulation and experimental study on multi-pass stagger spinning of internally toothed gear using plate blank, J. Mater. Process. Technol. 229 (2015) 450-466. 